This study used 103 employees from a large electronics firm as subjects in examining relative efficacy of 3 methods of benefit communication. Use of ANOVA revealed significant differences in benefit knowledge between experimental and control groups at the posttests. There was little relationship found between benefit knowledge and benefit satisfaction. Implications of these findings for practitioners and researchers are discussed.

\title{
A Determination of the Relative Efficacy of Different Techniques for Employee Benefit Communication
}

Russell W. Driver

University of Oklahoma

THAT THE GREATEST ONGOING EXPENSE for most organizations is that for wages and salaries is common knowledge. When it is considered that an amount equal to 36.7 percent of wages and salaries was spent for benefit payments in 1977 ( $E m$ ployee Benefits 1977,1978 ), it is no surprise to find that interest in benefits seems to be increasing exponentially along with the percentages.

Over the two decades from 1957 to 1977 the same U.S. Chamber of Commerce survey revealed that benefits as a percent of payroll rose 78 percent. Reflecting inflation, cents per payroll hour rose 391 percent in the same period, and dollars per year per employee rose 390 percent. The estimated total of employee benefits payments in 1977 in the U.S. was $\$ 310$ billion.

The impetus is thus provided for organizations to be vitally interested in getting as good a return as possible on such large investments. When the magnitude of dollars involved in an area such as benefits is so great, there is also good reason to posit interest by organizations in results of sound research on effective methods of benefit plan presentation to employees.

There are many objectives which organizations seek to accomplish through their benefit programs, including such things as improving employee morale, reducing turnover, attracting good employees, increasing job satisfaction, and keeping unions out (Geisler, 1975; Huseman and Hatfield, 1978; Huseman, 
Hatfield, and Driver, 1978). It is obvious that such objectives could not be attained without employee knowledge of benefits, and there is ample evidence that employee awareness or understanding of benefits is not very high (Holley and Ingram, 1973; Kulick and Lewis, 1973, cited in Nash and Carroll, 1975; and Sloane and Hodges, 1968). One method of rectifying that situation is to improve benefit communication.

Organizations assign high priority to benefit communication partly in an effort to increase return on investment. Communication of benefits ranked second in importance only to "company news and future prospects" in the internal communication programs of 219 U.S. corporate personnel directors responding to a recent survey (Miner, 1975).

The focus of this research was to investigate the relative effectiveness of different means of benefit communication. Specifically, comparisons were made between (1) a group receiving benefit information via a slide presentation, (2) a group receiving the same information in the same manner but with spouses present, and (3) a group receiving only the ongoing benefit communication in the organization. The measures of effectiveness were: (1) knowledge of benefit information and (2) employee satisfaction with their benefits.

\section{METHODS OF COMMUNICATION}

The journalism and education literature has given a good deal of attention to the question of which methods of communicating are most effective. However, the results are often conflicting; thus interpretations that are generalizable are difficult. [An extensive review of this literature can be found in the author's Ph.D. dissertation, An Investigation of the Relative Efficacy of Various Techniques for Communicating Benefits to Employees: A Quasi-Experiment in a Field Setting, University of Georgia, 1978.] Most pertinent to the present purpose was the research of Huseman, Hatfield, and Driver (1978). Their survey of 354 benefit managers revealed that the most commonly used techniques for communicating benefits (e.g., booklets and brochures, employee publications, and benefit manuals) were different from those techniques which were perceived by the managers as being most effective (e.g., intermittent employee meetings, personal counseling sessions, and regular employee meetings). It is 
obvious that the former are principally one-way means of communicating while the latter are primarily two-way.

The literature both within and outside the organizational context led to the conclusions that: (1) a combination of communication channels is usually better than a single channel, and (2) the attribute of directionality of the communication has a bearing on its effectiveness (Dahle, 1954; Hartman, 1961; Hsia, 1968; Huseman et al., 1978; Level, 1972; Levie and Dickie, 1973; Melcher and Beller, 1972; and Pacilio, 1977). Thus, it was determined that those two findings would be incorporated in the communication treatments administered at the subject organization (hereinafter referred to as Allied Computer and Electronics or ACE).

A technique of benefit communication unique to one of ACE's divisions was a slide presentation conducted during managers' meetings. In a variation of that, employee spouses attended. Both those methods has the two-way directionality attribute and involved use of multiple channels. The common, ongoing system of benefit communication was a combination of several techniques such as use of booklets and brochures, employee publications, computerized statement, and bulletin boards, which all have primarily a one-way attribute.

\section{RESEARCH OBJECTIVES}

The literature review led to the belief that a two-way attribute inherent in a benefit communication method would be superior to a method using primarily one-way communication. As a result, the research hypothesis formed was that:

Subjects receiving benefit communication via a slide presentation would have significantly greater benefit knowledge than those subjects receiving benefit knowledge via the ongoing benefit communication in the organization.

Three research questions (RQ) needing attention were:

RQ1: Will there be a significant difference in benefit knowledge between the experimental groups receiving the slide presentation, one of which will have spouses present?

RQ2: Will there be a significant retention of benefit knowledge over time resulting from the slide presentations? 
RQ3: What is the relationship between benefit knowledge and satisfaction with one's benefits?

\section{METHOD}

\section{Subjects}

For this research three groups of subjects (Ss) were selected from 2,800 employees in an ACE manufacturing plant and laboratory located in the southeastern U.S. They were selected by the plant personnel office with guidance provided by this researcher. The primary consideration was that the groups had never received a benefits slide presentation while at ACE. A secondary consideration was that of using natural work groups which could receive the treatment (benefit presentation) during the normal course of events at a meeting called by their manager. A final consideration was that each group be composed of employees holding a variety of jobs so that results could be more generalizable to the rest of ACE and to other organizations as well. Clearly, a quasi-experimental design is the result (Cook and Campbell, 1976).

Group One $(n=26)$ received the regular meeting with benefit presentation treatment, Group Two $(n=35)$ received the treatment with the opportunity for spouse participation, and Group Three $(n=42)$ was the "business as usual," no treatment, control group. All Ss were salaried, white collar employees. Some differences were noted among the groups' demographic profiles. Ss in Group One had a lower level of education than Ss in the other two groups, while Group Three Ss had fewer years tenure at ACE. Group Two Ss had retained their same job title (position) for a longer period, were older, and had proportionately fewer females. However, changes in benefit communication effectiveness were not judged as attributable to these differences.

\section{Procedure}

The procedure used for this investigation was the nonequivalent, untreated control group design with pretest and posttests (Cook and Campbell, 1976). All three phases (a pretest at $T_{1}$ and two posttests, one at each of $\mathrm{T}_{2}$ and $\mathrm{T}_{3}$ ) of the inquiry were conducted in the plant's main conference room. There were two 
weeks between $T_{1}$ and $T_{2}$ and three weeks between $T_{2}$ and $T_{3}$. Measures of knowledge of benefits and satisfaction with benefits were taken at all three points in time for each group.

\section{Pretest $\left(\mathrm{T}_{1}\right)$}

At the pretest Ss were informed by the plant Compensation and Benefits Manager of the procedure to be followed during the benefit communication study over the following five weeks. The author then read instructions for completing the booklet containing the instruments for the pretest measures. Upon completion of the booklets Ss individually returned to their work.

\section{Treatments and First Posttest $\left(\mathrm{T}_{2}\right)$}

Approximately two weeks after the pretest, the treatments were administered. The treatments consisted of communicating certain of ACE's benefits to Groups One and Two using the methods described earlier: (1) a regular slide presentation and (2) special slide presentations with employees where spouses were invited to attend. No treatment per se was administered the control group (Group Three). However, Group Three was used in this research as an experimental group in the analysis and conclusions because they represented those Ss receiving benefit information only through ACE's normal means and could be compared on that basis with the other two groups.

The treatments (slide presentations) were administered by ACE's benefit personnel in an attempt to keep from altering the work environment of the groups and to insure standardization of treatments. The presentation consisted of 62 slides. A twoway flow of communication was greatly encouraged via the relaxed atmosphere of the session and repeated invitations for questions and comments by the presenters. Observations by those conducting the sessions led to the conclusion that a high degree of dialogue resulted. Upon completion of the benefit discussions, the author administered the instrument booklet.

\section{Second Posttest $\left(\mathrm{T}_{3}\right)$}

Three weeks after the first posttest a second one was conducted to determine persistence of any effects found at the first posttest. Essentially the same instrument booklet was admini- 
stered by the author to all Ss at this third session that had been used at the previous two sessions.

\section{Instruments}

There were four parts to the booklet which contained the instruments. Parts I and II were measures of benefit satisfaction, Part III was a benefit knowledge measure, and Part IV was primarily for gathering demographic data.

Part I was a semantic differential (SD) scale and was developed by this author following Osgood, Suci, and Tannenbaum (1957). Brinton (1969), Reitz (1971, 1977), Scott (1967), Scott and Rowland (1970), Staats and Staats (1958), and Tannenbaum $(1966,1969)$ have all used the SD successfully for purposes similar to those in this study. The scale used contained five concepts: (1) all the benefits as a package, (2) the family hospitalization plan, (3) the family dental plan, (4) the major medical plan, and (5) the sickness and accident plan. The same seven bipolar adjective scales were used for each concept: good-bad, valuable-worthless, adequate-inadequate, important-unimportant, superior-inferior, effective-ineffective, and appreciated-unappreciated. Reliability (test-retest) of the $\mathrm{SD}$ at $\mathrm{T}_{1}$ and $\mathrm{T}_{2}$ as a measure of stability was found to be quite good for a satisfaction measure $\left(r_{t t}=.75, p=.001\right)$.

Part II was a Likert scale measure of benefit satisfaction which had been used by ACE for many years during annual surveys. It provided a second measure of satisfaction for statistical comparison. This instrument was also quite reliable $\left(r_{t t}=.75, p=.001\right)$. The two different methods of measuring the benefit satisfaction construct (Parts I and II) correlate well $(r=.72, p=.001)$, showing that the measures have a high degree of convergent validity.

Part III was a 25-item multiple choice test of Ss' detailed knowledge of their benefits (see Dahle, 1954; Holley and Ingram, 1973; Sheard, 1966; and Sloane and Hodges, 1968 for previous use of similar instruments for similar purposes). It was decided that essentially identical forms would be used at all three points in time. Therefore, a precaution was taken against familiarity with questions over time being a plausible alternative explanation of findings. The first 20 questions remained unchanged throughout the research while at each session the last 5 questions were changed. However, the first 20 were the only ones used in most of the data analysis. 
It was appropriate that reliability for the knowledge test be determined using both test-retest and internal consistency measures. The retest correlation at $T_{1}$ and $T_{2}$, using responses to only those 20 questions which were identical at $T_{1}, T_{2}$, and $T_{3}$, was considered "fairly" good ( $\left.\mathrm{r}_{\mathrm{tt}}=.66, \mathrm{p}=.001\right)$ by Kerlinger's (1973) criterion. Additionally, Guilford (1954) states that "because of chance success in responding to multiple-choice items, we expect them to be less reliable than ... other forms in which chance success is unimportant" (p. 392). Reliability in the internal consistency sense was excellent. Using the KuderRichardson formula 20, internal consistency of the knowledge test was found to be .96 .

It is generally agreed that achievement test validity is best accomplished by use of content validity (Downie and Heath, 1974; Guilford, 1954; and Kerlinger, 1973). The kinship between achievement tests and the benefit knowledge test in this research is obvious. Judgments of six "experts" agreed that this instrument was content valid.

Part IV was primarily questions of a demographic nature. The demographic questions were a replica of a portion of ACE's annual survey and asked for age, sex, organization tenure, position tenure, marital status, race, and education.

\section{Analysis}

To test for differences between experimental groups (the hypothesis) two separate one-way ANOVA's were run, one each at $\mathrm{T}_{1}$ and $\mathrm{T}_{2}$. Since those in Group Two who did not take their spouses to the slide presentation (or were not married) were in essence receiving the same treatment as those in Group One, a t-test between those in Group Two with spouses present and those in Group Two without spouses present was run to evaluate the first research question (RQ1). Additionally, that question was further answered in the ANOVA's mentioned above. The retention question (RQ2) was tested through a third ANOVA at $\mathrm{T}_{3}$ and a t-test between $\mathrm{T}_{2}$ and $\mathrm{T}_{3}$ for Groups One and Two combined. Correlations of both benefit satisfaction measures with the knowledge measure were calculated to determine the relationship between the constructs (RQ3). 


\section{RESULTS}

Figure 1 presents mean scores for knowledge at all three points in time. The ANOVA's corresponding to Figure 1 are in Table 1 . There was a marginal probability $(p=.106)$ that no differences existed between groups at the pretest $\left(T_{1}\right)$. The Scheffe test allows a stronger statement to that effect by not finding any subset apart from the three groups together.

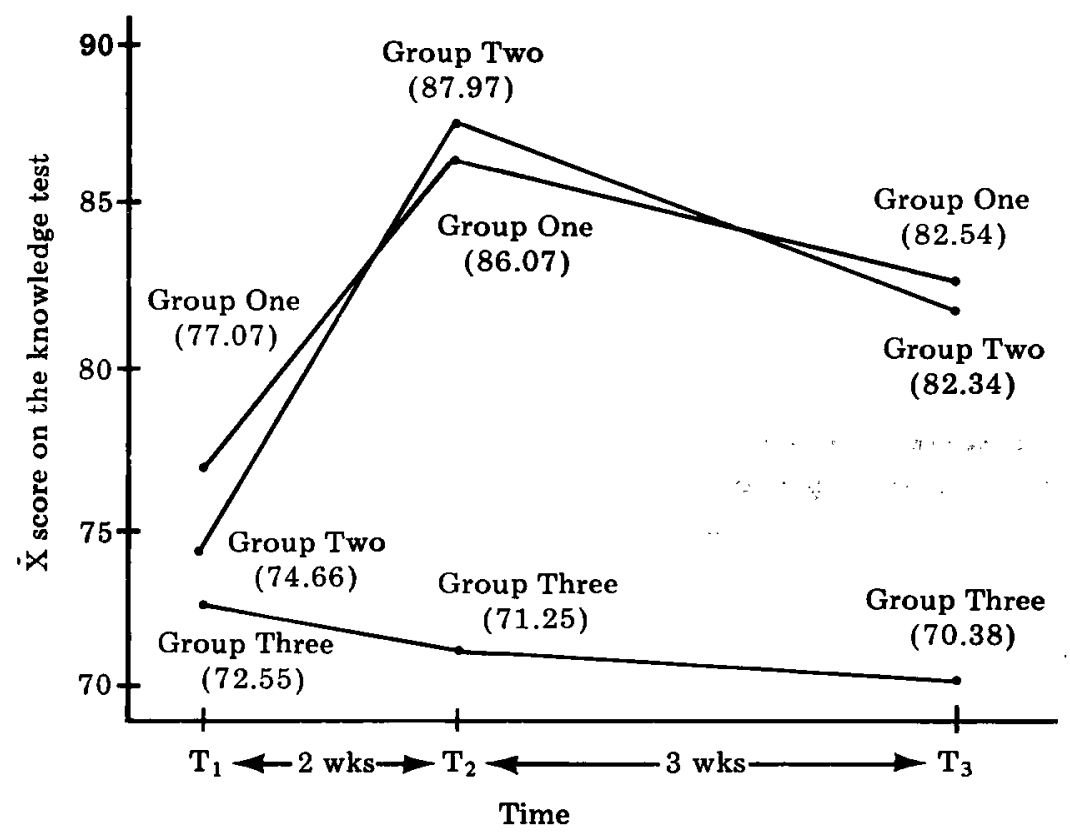

Figure 1

Results of the Benefit Knowledge Test

At $T_{2}$ it is clear that there was a significant difference between groups $(\mathrm{p}<.001)$. Further, the significance found at $T_{2}$ persisted to $T_{3}$. A t-test between scores of Group One and Group Two subjects (combined) at $\mathrm{T}_{2}$ and $\mathrm{T}_{3}$ showed a significant difference $(p<.000)$, indicating that the decrease from $T_{2}$ to $T_{3}$ for those two groups, as seen in Figure 1, was significant. 
Table 1

One-way ANOVA of All Groups

(Dependent Variable-Knowledge)

\begin{tabular}{lllllll}
\hline Source & df & $\begin{array}{l}\text { Sum of } \\
\text { Squares }\end{array}$ & $\begin{array}{c}\text { Mean } \\
\text { Squares }\end{array}$ & F & p \\
\hline
\end{tabular}

AT THE PRETEST

$\begin{array}{crrrrr}\text { Between groups. . } & 2 & 331.00 & 165.00 & 2.30 & .106 \\ \text { Within groups . . . } & 100 & 7199.58 & 72.00 & & \\ \text { Total. . . . . . } & 102 & \mathbf{7 5 3 0 . 5 8} & & & \\ \end{array}$

AT THE FIRST POSTTEST

$\begin{array}{crrrrr}\text { Between groups. . } & 2 & 6354.53 & 3177.27 & 60.88<.001 \\ \text { Within groups . . } & 100 & 5218.74 & 52.19 & & \\ \text { Total. . . . . . } & 102 & \mathbf{1 1 5 7 3 . 2 7} & & \end{array}$

AT THE SECOND POSTTEST

$\begin{array}{rrrrrr}\text { Between groups. . } & 2 & 3609.48 & 1804.74 & 23.87<.001 \\ \text { Within groups . . } & 100 & 7562.25 & 75.62 & & \\ \text { Total. . . . . . } & 102 & \mathbf{1 1 1 7 1 . 7 3} & & \end{array}$

Table 2 shows that there was no difference in knowledge scores between those in Group Two who had their spouses with them at the presentation and those who did not. That lack of difference is evident at all points in time. Additionally, Group Two scores were not different from Group One scores at any point in time.

Table 2

T-Tests Between Factions in Group Two

\begin{tabular}{llllllll}
\hline Time & $\mathbf{n}$ & $\dot{\mathbf{x}}$ & Deviation & Error & value & df & $\begin{array}{l}\text { 2-tail } \\
\text { prob. }\end{array}$ \\
\hline
\end{tabular}

$T_{1}$

$\begin{array}{lrrrrrrr}\text { with spouses. . . } & 15 & 75.72 & 10.08 & 2.60 & .57 & 27.89 & .574 \\ \text { without spouses . } & 20 & 73.87 & 8.81 & 1.97 & & & \end{array}$


Table 2, Continued

\begin{tabular}{|c|c|c|c|c|c|c|c|}
\hline Time & $\mathbf{n}$ & $\dot{\mathbf{x}}$ & $\begin{array}{c}\text { Std. } \\
\text { Deviation }\end{array}$ & $\begin{array}{l}\text { Std. } \\
\text { Error }\end{array}$ & $\begin{array}{c}t \\
\text { value }\end{array}$ & df & $\begin{array}{l}\text { 2-tail } \\
\text { prob. }\end{array}$ \\
\hline $\begin{array}{l}\quad \mathrm{T}_{2} \\
\text { with spouses. . . . } \\
\text { without spouses . }\end{array}$ & $\begin{array}{l}15 \\
20\end{array}$ & $\begin{array}{l}88.93 \\
87.26\end{array}$ & $\begin{array}{l}6.17 \\
6.50\end{array}$ & $\begin{array}{l}1.59 \\
1.45\end{array}$ & .77 & 31.13 & .446 \\
\hline $\begin{array}{l}\quad \mathrm{T}_{\mathbf{3}} \\
\text { with spouses. . . . } \\
\text { without spouses . }\end{array}$ & $\begin{array}{l}15 \\
20\end{array}$ & $\begin{array}{l}82.13 \\
82.50\end{array}$ & $\begin{array}{l}5.42 \\
8.28\end{array}$ & $\begin{array}{l}1.40 \\
1.85\end{array}$ & -.16 & 32.51 & .875 \\
\hline
\end{tabular}

Finally, Table 3 shows the lack of correlation between either of the benefit satisfaction measures and benefit knowledge at any point in time. An attempt to correlate change scores between $T_{1}$ and $T_{2}$ for knowledge and satisfaction also failed to indicate a relationship.

Table 3

\section{Pearson Correlation of Benefit Satisfaction with Benefit Knowledge}

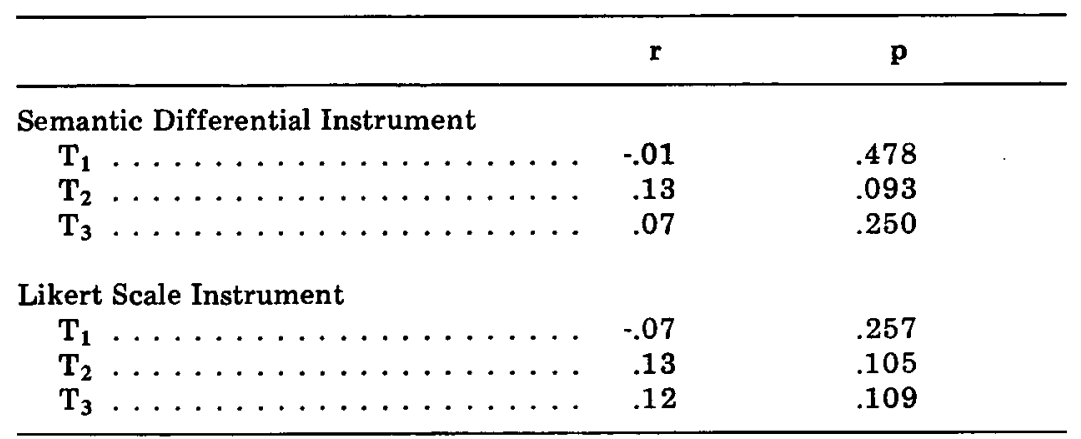

\section{DISCUSSION}

\section{The Hypothesis and RQ1}

Is it clear from the results that there was good support for the hypothesis that the slide presentations were superior to the ongoing benefit communication at $\mathrm{ACE}$. The differences at the first 
posttest attest to that fact. Moreover, the lack of differences at the pretest eliminate many plausible alternative explanations for the findings at $T_{2}$ and $T_{3}$. The format of a slide presentation (regardless of whether spouses are present) appears to be far superior, in terms of benefit knowledge gained, to the ongoing method of benefit communication at ACE.

The finding that spouse presence had no effect on knowledge gained nor retained is a contradiction to the social facilitation literature which tells us that presence of a "significant other" should have some effect. Presumably most people are a significant other to their spouses.

Dahle (1954), Hartman (1961), Hsia (1968), Level (1972), and Pacilio (1977) all found that use of a combination of channels is usually superior to using only one. In the present research, both the ongoing method of communicating benefits and the treatments included a combination of channels; yet the treatment groups were far superior on the knowledge criterion at the posttests. Therefore, one may have to agree with Levie and Dickie (1973) that it was the attribute of two-way versus oneway communication that made the difference, not the multiplicity of channels used as those authors noted above may have posited. There is further evidence for the attribute supposition from Pacilio's (1977) work, where method of communicating involving a two-way flow was superior to one which had no such attribute.

\section{RQ2}

There was also support for an affirmative answer to the question of whether a significant difference in retention of benefit knowledge would be found. It is not known how long it would take the knowledge to drop back to the pretest level, but the fact that it dropped significantly for Groups One and Two from $T_{2}$ to $T_{3}$ is evidence that the decrease was not merely an artifact of regression. Therefore, it could be assumed that the decline would continue until there was no longer a significant difference.

\section{RQ3}

There is a prevalent thought at ACE and many other organizations that greater investments in benefits will be returned with 
profit through the greater productivity (or some other manifestation of "appreciation") induced by improved attitudes which result from more and better benefits. This study did not support that contention.

There appears to be little relationship between benefit knowledge and satisfaction with one's benefits. This supports the supposition of Huseman and Hatfield (1978) that the relationship is "tenuous." Apparently there is a difference in knowing about one's benefits and being satisfied with them.

\section{CONCLUSIONS}

Several conclusions from this research seem warranted at this point.

1. It was found that the essentially two-way flow of communication in a manager's meeting via a benefit slide presentation was far superior in terms of knowledge imparted to employees than was the ongoing benefit communication in the organization which consisted of a combination of 14 other techniques. Additionally, it was shown that there was a significant retention of that knowledge over a three-week period.

These conclusions provide grounds for organizations to consider more extensive use of such two-way communication modes as the slide presentation. The possible increase in cost over their present system of benefit communication may prohibit its use. However, that is a cost/benefit analysis necessary to be performed individually by those organizations considering such a change. A primary consideration in their decision should be whether that change would facilitate attainment of whatever goal they may have in mind for their benefit communication program.

2. "Management appears to be hopeful that the costs for benefits are being returned to the company in more effective performance and improved attitudes" (Sheard, 1966, p. 614). However, this research was able to identify no relationship between benefit knowledge and benefit satisfaction. Management's assumption of a relationship between benefits provided and attitudes has not been validated. Thus, to the extent that an organization's benefits are being improved with the intention of improving employees' attitudes (at least toward their benefits), it appears that this goal is not being attained. 
It may be more likely that a change in attitude would appear in satisfaction with the organization rather than with the benefits themselves. Without the relationship of benefit knowledge and benefit satisfaction, there may be no relationship between such knowledge and satisfaction with the organization. However, one's satisfaction with the benefits would not necessarily have to increase prior to or commensurate with an increase in organization satisfaction. A study of the relationship among (1) benefit knowledge, (2) benefit satisfaction, and (3) satisfaction with the organization may yield informative results.

3. The lack of support by employees' "significant others" (spouses) in terms of knowledge attained or retained is a contradiction to current thinking in social facilitation. As a result of this study, more research may be warranted in determining why such thinking did not hold up in this inquiry.

4. Though the present study was longitudinal in nature, the length of time between the posttests was not long enough to determine how long it would take for Ss in Groups One and Two to revert to their original level of knowledge. It may never revert to that point. Is there a plateau that develops before termination of the regression? The length of such studies could be increased to give a greater range of information. Frequency of repeat slide presentations to employees could be based on findings from such research.

\section{$\uparrow+$}

\section{NOTES AND REFERENCES}

Brinton, J. E. In J. G. Snider and C. E. Osgood (Eds.), Semantic Differential Techniques: A Sourcebook. Chicago: Aldine, 1969.

Cook, T. and D. Campbell. "The Design and Conduct of Quasi-experiments and True Experiments in Field Settings." In M. Dunnette (Ed.), Handbook of Industrial and Organizational Psychology. Chicago: RandMcNally, 1976.

Dahle, T. L. "An Objective and Comparative Study of Five Methods of Transmitting Information to Business and Industrial Employees." Speech Monographs 1954, Vol. 21, No. 1, 21-28.

Downie, N. M. and R. W. Heath. Basic Statistical Methods (4th ed.). New York: Harper \& Row, 1974.

Employee Benefits 1977. Washington, DC: Chamber of Commerce of the United States, 1978.

Geisler, T. L. "An Evaluation of Benefit Communications Programs" (Doctoral dissertation, University of Missouri-Columbia, 1975). Disserta- 
tions Abstracts International 1976, Vol. 36, 6343A-7011A. (University Microfilms No. 76-7491, 219).

Guilford, J. P. Psychometric Methods (2nd ed.). New York: McGrawHill, 1954.

Hartman, F. R. "Single and Multiple Channel Communication: A Review of Research and a Proposed Model." Audio-Visual Communication Review, 1961, Vol. 9, 235-262.

Holley, W. H., Jr., and E. Ingram, II. "Communicating Fringe Benefits." The Personnel Administrator, March-April 1973, 21-22.

Hsia, H. J. "On Channel Effectiveness." Audio-Visual Communication Review, 1968, Vol. 16, 245-267.

Huseman, R. C., and J. D. Hatfield. "Communicating Employee Benefits: Directions for Future Research." The Journal of Business Communication, 1978, Vol. 15, No. 4, 3-17.

- and R. W. Driver. "Getting Your Benefit Programs Understood and Appreciated." Personnel Journal, 1978, Vol. 57, 560-566, 578.

Kerlinger, F. Foundations of Behavioral Research (2nd ed.). New York: Holt, Rinehart and Winston, 1973.

Level, D. A., Jr. "Communication Effectiveness: Method and Situation." The Journal of Business Communication, 1972, Vol. 10, No. 1, 19-25.

Levie, W. H., and K. E. Dickie. "The Analysis and Application of Media." In R. M. W. Travers (Ed.), Second Handbook of Research on Teaching. Chicago: Rand-McNally, 1973.

Melcher, A. J. and R. Beller. "Toward a Theory of Organization Communication: Consideration in Channel Selection." In $\mathrm{H}$. Koontz and C. O'Donnel (Eds.), Management: A Book of Readings (3rd ed.). New York: McGraw-Hill, 1972.

Miner, M. G. Employee Communications (Personnel Policies Forum Survey No. 110, Bureau of National Affairs). Washington, DC, 1975.

Nash, A. J. and S. J. Carroll. The Management of Compensation. Belmont, CA: Wadsworth, 1975.

Osgood, C., G. Suci, and P. Tannenbaum. The Measurement of Meaning. Urbana, IL: University of Illinois Press, 1957.

Pacilio, J., Jr. "The Effect of Three Methods of Instruction on Task Performance." Proceedings of the 37th Annual Meeting of the Academy of Management, 1977, 380-384.

Reitz, H. J. "Managerial Attitudes and Perceived Contingencies Between Performance and Organizational Responses." Proceedings of the 31 st Annual Meeting of the Academy of Management, 1971, 227-238.

- Behavior in Organizations. Homewood, IL: Irwin, 1977.

Scott, W. E., Jr. "The Development of Semantic Differential Scales as Measures of Morale." Personnel Psychology, 1967, Vol. 20, 179-198.

- and K. M. Rowland. "The Generality and Significance of Semantic Differential Scales as Measures of 'Morale." Organizational Behavior and Human Performance, 1970, Vol. 5, 516-591.

Sheard, J. L. "Relationship Between Attitude and Knowledge in Employee Fringe Benefit Orientation." Personnel Journal, 1966, Vol. 45, 614-617.

Sloane, A. A. and E. W. Hodges. "What Workers Don't Know About Employee Benefits." Personnel, 1968, Vol. 45, No. 6, 27-34. 
Staats, A. and C. Staats. "Attitudes Established by Classical Conditioning." Journal of Abnormal and Social Psychology, 1958, Vol. 57, 37-40.

Tannenbaum, P. H. "Mediated Generalization of Attitude Change via the Principle of Congruity." Journal of Personality and Social Psychology, 1966, Vol. 3, 493-499.

- "Initial Attitude Toward Source and Concept as Factors in Attitude Change Through Communication." In J. G. Snider and C. E. Osgood (Eds.), Semantic Differential Technique: A Sourcebook. Chicago: Aldine, 1969.

\section{CALL FOR PAPERS}

\section{Communication Training and Consulting in} Business, Industry, and Government

This book, to be published by ABCA, will focus on the essential aspects of organizational communication training and consulting. Both in-house training programs run by company trainers and those run by outside professionals will be examined. Proposals, syllabi, letters of inquiry, contracts, course certificates, sample audit reports, audit questionnaires, audit interviews, etc., dealing with training programs in government, nonprofit organizations, business, and industry are welcome, as are essays dealing with the following areas:

1. Independent training services (ferreting out prospects, making contact, setting prices, submitting proposals, etc.).

2. Training program scope (written, oral, aural, reading, nonverbal, etc.).

3. Training delivery variations (seminars, lectures, workshops, one-day intensive, multiple week, etc.).

4. Training program audience (top- middle- lower-management, staff, technicians, scientists, engineers, etc.).

5. Nontraining aspects of consulting (editing, troubleshooting, communication auditing/analysis, freelancing, etc.).

6. Ethics and politics in consulting/training.

7. Communication needs perceived by business.

8. International consulting (both training programs and auditing/ analysis).

Please send your material (and a self-addressed, stamped envelope) to: William Buchholz, Department of English, Bentley College, Waltham, MA 02154. 